\title{
Intertrochanteric fracture fixation with Dynamic Hip Screw: Is tip-apex distance measurement useful for predicting fixation failure?
}

Goh KL, Zamzuri Z, Mohd Ariff S, Mohamed Azril MA

Department of Orthopaedics, Traumatology and Rehabilitation, Kulliyyah of Medicine, International Islamic University Malaysia.

\section{ABSTRACT}

Introduction: Application of dynamic hip screw (DHS) implant for the treatment of unstable intertrochanteric fractures continues to raise concern related to risk of lag screw cut-out with or without subsequent damage to the acetabulum. Measurement of tip-apex distances (TAD) has been recommended to guide the optimal placement of lag screw and to predict subsequent risk of screw cut-out. In this study, the value of TAD was evaluated to verify its usefulness. Methods: This is a retrospective study of 33 consecutive patients with intertrochanteric fracture treated with DHS. Demographic data of the patients were traced from their case notes. Post-operative radiographs were reviewed by focusing on measurement of TAD on anteroposterior and lateral radiographs. Radiographs at one year follow-up were reviewed to depict any fixation-related failure or complication. Results: Fifty two percent of patients did not achieved the recommended TAD of $\leq 25 \mathrm{~mm}$. The mean post-operative TAD was $25.9 \mathrm{~mm}$ and elderly patients were likely to achieve TAD of $\leq 25 \mathrm{~mm}$. The overall complication rate of $6 \%$ was attributed to screw cut-out in two cases. The unstable left-sided fracture was identified to be a potential risk for screw cut-out or migration. Conclusion: TAD is a valuable measurement to guide optimal placement of lag screw during DHS fixation of intertrochanteric fracture.

KEYWORDS: Intertrochanteric fracture, dynamic hip screw, tip-apex distance, screw cut-out. INTRODUCTION

Intertrochanteric fractures represent the commonest proximal femoral fractures encountered in orthopaedic practice. In Malaysia, elderly subjects are commonly afflicted with a prevalence of 90 per 100,000 population. ${ }^{1}$ Dynamic hip screw (DHS) fixation is currently the gold standard treatment as this fixation device has been reported to have low complication rate when properly used for fixation of stable intertrochanteric fractures. ${ }^{2}$ However, its application for the unstable subset of

Corresponding author:

Dr Goh Kian Liang

Department of Orthopaedics, Traumatology

and Rehabilitation,

Kulliyyah of Medicine,

International Islamic University Malaysia,

Jalan Sultan Ahmad Shah,

Bandar Indera Mahkota,

25200 Kuantan, Pahang,

Tel. No. (+60)019-9211838

Fax No. 09-5144451

Email: kianliang@iium.edu.my intertrochanteric fractures remains controversial with concern related to high-risk of fixation failures: lag screw cut-out with subsequent damage to the acetabulum, lateral back-out of lag screw, implant disengagement, malunion and non-union. ${ }^{3}$ The tip-apex distance (TAD), which is a measurement of the position of the tip of the lag screw in femoral head, has been shown to be a reliable predictor of screw cut-out when the threshold value is more than $25 \mathrm{~mm} .{ }^{4}$ The objective of this study is to determine whether the TAD has a significant influence on the outcome of intertrochanteric fractures in a local population.

\section{MATERIALS AND METHODS}

Medical records of 33 adults and elderly patients admitted for intertrochanteric fracture and treated with DHS from January 2005 to December 2010 were reviewed. Subjects above 18 years of age were included and those with multiple long bone fractures, segmental fracture of the femur, pathological fractures and previous hip surgery were excluded. 
The radiographic measurement of TAD according to the technique described by Baumgaertner et al. ${ }^{4}$ was used. The TAD measurement takes into consideration both the location and depth of screw penetration. The TAD was defined as the sum of the distances from the apex of the femoral head to the tip of the lag screw on anteroposterior and lateral radiographs. Measurement was corrected for the magnification by using the known diameter of the shaft of lag screw as reference (Figure 1). The postoperative TAD was compared with the TAD at one year post-surgery to indicate screw migration.

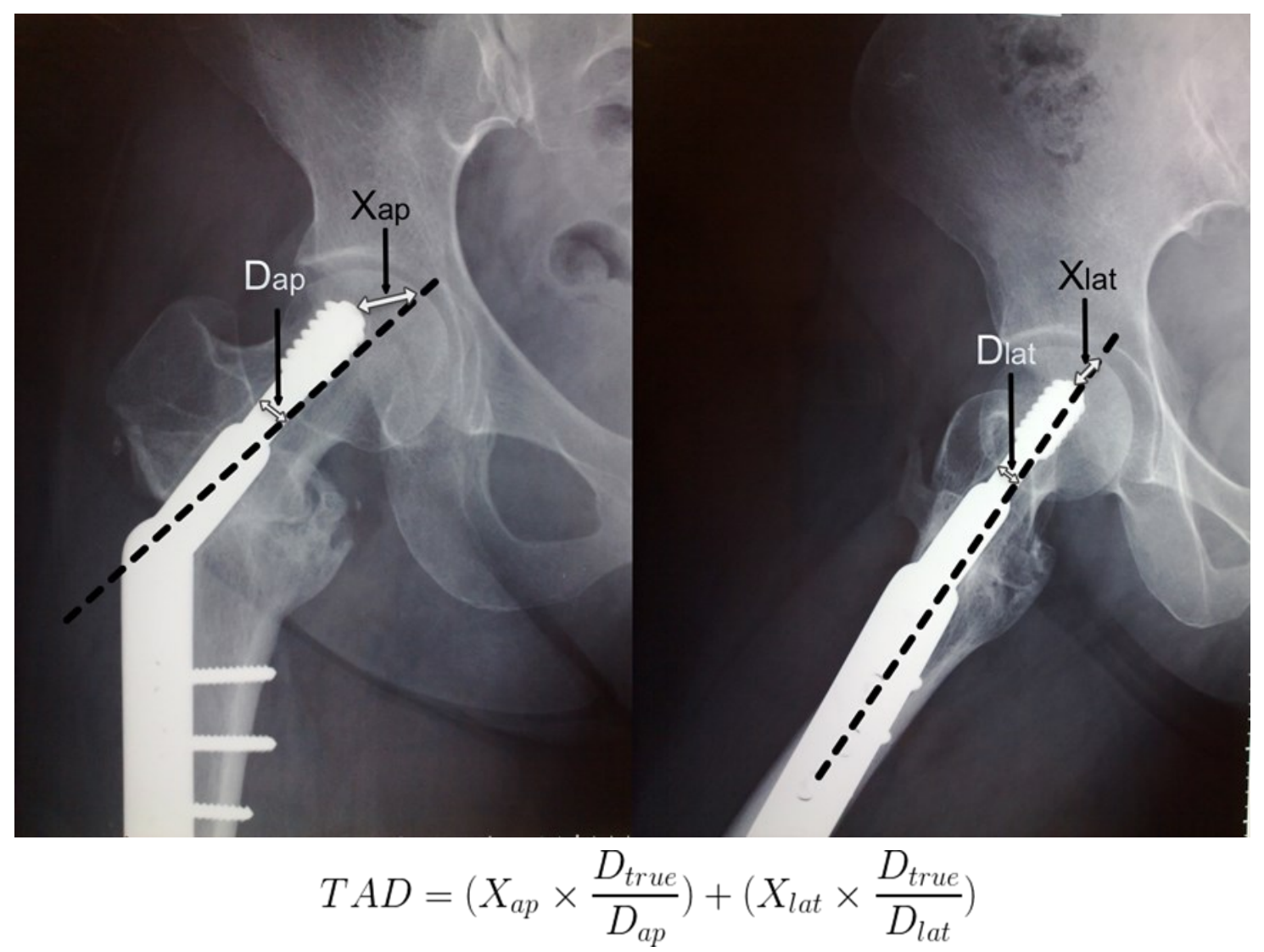

Figure 1: Method of measuring and calculating the TAD

The TAD of $25 \mathrm{~mm}$ was used as reference threshold value to predict the risk of screw cut-out. Statistical analysis was performed using PASW/SPSS version 18 for windows. For all test, statistical significance was considered at $p$-value of $<0.05$.

\section{RESULTS}

There were 20 male patients $(61 \%)$ and 13 female patients (39\%) with mean age of 59 years (range: 18-89 years). Malay patients accounted for $67 \%$ followed by Chinese (24\%), Indian (6\%) and foreigners $(2 \%)$. The right-sided fractures were encountered in $52 \%$ of cases. The most common mechanism of injury in elderly patients indicated fragility fracture due to low-energy fall $(61 \%)$. Motor vehicle accident (33\%) and industrial accident (6\%) accounted for the mechanisms of injury in young adults.

Stable fractures as defined according to the $A O$ classification system, accounted for $58 \%$ of 33 fractures. Fracture personality factors: side of fracture and fracture stabilty, were not found to influence the TAD (Table 1). We acknowledge that this is most likely due to the relatively low number of failures in our study. 
Table 1: Overview of the patients $(\mathrm{N}=33)$ with and without screw cut-out

\begin{tabular}{|c|c|c|c|}
\hline & \multicolumn{2}{|c|}{ TAD } & \multirow[t]{2}{*}{$p$-value } \\
\hline & $\leq 25 \mathrm{~mm}$ & $>25 \mathrm{~mm}$ & \\
\hline Age & $68.3(13.78)$ & $50.3(21.31)$ & 0.007 \\
\hline \multicolumn{4}{|l|}{ Race } \\
\hline Malay & $8(36 \%)$ & $14(6.4 \%)$ & \\
\hline Chinese & $7(88 \%)$ & $1(22 \%)$ & $0.054^{\square}$ \\
\hline Indian & $1(50 \%)$ & $1(50 \%)$ & \\
\hline Others & $0(0 \%)$ & 1 (100\%) & \\
\hline \multicolumn{4}{|l|}{ Gender } \\
\hline Male & 7 (35\%) & 13 (65\%) & $0.058^{*}$ \\
\hline Female & $9(69 \%)$ & $4(31 \%)$ & \\
\hline \multicolumn{4}{|l|}{ Side } \\
\hline Right & 7 (41\%) & 10 (59\%) & 0.387 \\
\hline Left & $9(56 \%)$ & 7 (44\%) & \\
\hline \multicolumn{4}{|c|}{ Fracture Stability } \\
\hline Stable & $10(53 \%)$ & $9(47 \%)$ & 0.579 \\
\hline Unstable & $6(43 \%)$ & $8(57 \%)$ & \\
\hline \multicolumn{4}{|c|}{ Screw cut-out } \\
\hline No & $16(52 \%)$ & $15(48 \%)$ & $0.48^{*}$ \\
\hline Yes & $0(0 \%)$ & $2(100 \%)$ & \\
\hline
\end{tabular}

${ }^{*}$ Fisher exact test, exact sig. (1-sided), ${ }^{\circ}$ Computed for $2 \times 2$ table (Malay vs The rest)

The recommended TAD distance of $\leq 25 \mathrm{~mm}$ was not achieved in $52 \%$ of patients. The mean immediate post-operative TAD $25.9 \pm 8.68 \mathrm{~mm}$ was not significantly altered after one post-operative year (mean TAD $25.5 \pm 8.68 \mathrm{~mm}$ ). Elderly patients with mean age of 50 years have higher likelihood to achieve TAD of < than $25 \mathrm{~mm}$ ( $p$-value of 0.007 ). Two patients from with TAD of $>25 \mathrm{~mm}$ developed screw cut-out/superior migration giving rise the overall complication rate of $6 \%$ but it was not statistically significant when compared with those with TAD of $<25 \mathrm{~mm}$. This outcome is most likely due to the relatively low number of failures in our series. Patients with TAD of $<25 \mathrm{~mm}$ were free of complication. Other implant-related failures: acetabular penetration, implant breakage or disengagement, non-union and malunion were not observed.

\section{DISCUSSION}

Intertrochanteric fractures continue to be a 'disease' of elderly population with a raising trend of incidence attributable to an increasing aging population. ${ }^{5,6}$ Its predominant mechanism of injury, low-energy fall, indicates fragility fractures among elderly in our study population. Other studies have shown that most fractures were domestic injury affecting elderly individuals with either healthcompromised premorbid or poor ambulatory status, and more than $75 \%$ of fractures resulted from a fall while standing or walking. ${ }^{7-9}$

Prediction of the outcome of DHS fixation by radiographic measurements has been extensively studied. Measurement of TAD as described by Baumgaertner et al. ${ }^{4}$ has been used to guide an optimal placement of lag screw. It is importance to recognize that the TAD measurement is evaluated in two dimensions accounting for both the location and depth of lag screw penetration. A concentrically placed lag screw will have a lower TAD than an eccentrically placed screw.

In our study, only $48 \%$ of fixation managed to achieve TAD of $<25 \mathrm{~mm}$ and this was particularly a common occurrence in elderly patients. The reason for this occurrence probably related to the awareness that deeper placement of lag screw tip to engage subchondral bone has a strong purchase on the osteopenic bone in the elderly. We also found that our $6 \%$ complication rate was attributed to eccentric screw placement with TAD of more than $25 \mathrm{~mm}$. Study by Pervez et al. ${ }^{10}$ indicated that that low rate of screw cut-out was correlated with TAD of less than $20 \mathrm{~mm}$ and fracture reduction in valgus position. Similar results were duplicated by 
Chua et al. ${ }^{11}$ by emphasising a relationship between TAD threshold value of $>20 \mathrm{~mm}$ and risk of screw cut -out in Asian patients. The screw cut-out rate was found to be more than $20 \%$ if the TAD exceeded 25 $\mathrm{mm}$ as compared with TAD of $<20 \mathrm{~mm}$.

Fracture stability was not found to influence the final outcome of this study. The relationship between left-sided fracture and the development of unstable reduction due to re-displacement of fracture fragments has been highlighted by Mohan et $a{ }^{12}{ }^{12}$ It was speculated that left-sided fracture tended to have displacement of the proximal fragmant due to torque created by clockwise rotation of lag screw during its insertion.

In contrary, the torque effect of clockwise rotation of lag screw compresses the right-sided fracture site and hence increases stability of the fracture. Surgeons confronted with left-sided unstable intertrochanteric fractures should be aware of the possibilty of creating excessive torque effect during insertion of lag screw for the unstable fractures with eventual fixation of a non-anatomically reduced fracture. This can be addressed by provisionally fix the main fragments with a largediameter Kirschner wire to enhance stable reduction and to negate rotation during insertion of lag screw. Rehabilitation of a non-anatomically reduced unstable intertrochanteric fracture will endure significant torsional force. Torsional force acting on the head-neck segment of the proximal femur normally occurs during gait and this provides an explanation for the evolving superior migration and subsequent screw cut-out following fixation of an unstable fracture with a non-concentrically placed lag screw and a long TAD.

\section{CONCLUSIONS}

A satisfactory outcome of intertrochanteric fracture fixation can be expected with the use of DHS provided the lag screw is optimally placed. This interdependently requires anatomical reduction to impart inherent stable reduction and placement of lag screw tip enganging the subchondral bone in central-central positions on both AP and lateral radiographs.

\section{REFERENCES}

1. Lee JK, Khir A. The incidence of hip fractures in Malaysia above 50 years of age: variation in different ethnic groups. J Rheumatol 2007; 10: 300-5.

2. Harrington $P$, Nihal $A$, Singhania $A K$ et al. Intramedullary hip screw versus sliding hip screw for unstable intertrochanteric femoral fractures in the elderly. Injury 2002; 33: 23-8.

3. Baumgaertner MR, Curtin SL. Linskog DM. Intramedullary versus extramedullary fixation for the treatment of intertrochanteric hip fractures. Clin Orthop 1998; 348: 87-94.

4. Baumgaertner MR, Curtin SL. Linskog DM et al. The value of the tip-apex distance in predicting failure of fixation of peritrochanteric fractures of the hip. J Bone Joint Surg 1995; 77-A: 105864.

5. Koval KJ, Zuckerman JD. Hip fractures are an increasingly important public health problem. Clin Orthop 1998: 314: 2.

6. Rockwood PR, Horne JG, Cryer C. Hip fractures: a future epidemic. J Orthop Trauma 1990; 4: 388-93.

7. Aharonoff GB, Dennis MG, Elshinawy A et al. Circumstances of fall causing hip fractures in the elderly. Clin Orthop 1998; 314: 10-4.

8. Cumming RG, Klineberg RJ. Fall frequency and characteristics and the risk of hip fractures. J Am Acad Orthop Surg. 1994; 42: 774-8.

9. Michelson JD, Myers A, Jinnah $\mathrm{R}$ et al. Epidemiology of hip fracture among the elderly: risk factor for fracture type. Clin Orthop 1995; 311: 129-35.

10. Pervez H, Parker MJ, Vowler S. Prediction of fixation failure after sliding hip screw fixation. Injury 2004; 35: 994-8.

11. Chua YP, Kwan MK, Ng WM et al. Use of the tipapex distance in predicting dynamic hip screw cut-out in intertrochanteric fracture of the femur in Asian population. Malaysia Orthop $J$ 2011; 5: 24-7.

12. Mohan R, Karthikeyan R, Sonanis SV. Dynamic hip screw: does side make a difference? Effects of clockwise torque on right and left DHS. Injury 2000; 31: 697-9. 